\title{
Development of an injectable system based on elastin-like recombinamer particles for tissue engineering applications
}

\author{
Mariana B. Oliveira, ${ }^{a b}$ Wenlong Song, ${ }^{a b}$ Laura Martín, ${ }^{c d}$ Sara M. Oliveira, ${ }^{a b}$ Sofia G. Caridade, ${ }^{a b}$ \\ Matilde Alonso, ${ }^{c d}$ José C. Rodríguez-Cabello ${ }^{c d}$ and João F. Mano ${ }^{* a b}$
}

\author{
Received 11th November 2010, Accepted 22nd March 2011 \\ DOI: $10.1039 / \mathrm{c} 0 \mathrm{sm} 01302 \mathrm{a}$
}

\begin{abstract}
An elastin-like recombinamer (ELR) containing the RGD cell adhesion domain was used to fabricate microparticles by an innovative and affordable process based on the use of superhydrophobic surfaces. Two microparticles types with different crosslinking extents were prepared. The biological response was tested using an osteoblast-like cell line (SaOs-2) performing proliferation and alkaline phosphatase (ALP) quantification tests, as well as assessing cytotoxicity, morphology and cell distribution on the particles. The main goal of the work was the assessment of the in vitro formation of cell-induced microparticle aggregates that could provide indications for the possible formation of an in situ-forming scaffold upon implantation. ELR microparticles have been successfully obtained by deposition of a polymeric solution on bioinspired polystyrene superhydrophobic surfaces and two different crosslinking extents were achieved by controlling the time of exposure to the crosslinker. The crosslinking extent affected swelling behavior and the dynamic mechanical properties of the particles. SaOs-2 morphology, ALP expression, spatial distribution and ability to bind the microparticles together were dependent on the physicochemical properties of the microparticles: the more crosslinked condition was the most favorable for cell proliferation and to form a cell-induced aggregation scaffold, making these particles suitable to be applied in bone tissue engineering.
\end{abstract}

\section{Introduction}

Tissue engineering (TE) is a field that applies the principles of biology and engineering to the development of functional substitutes for damaged tissues. ${ }^{1}$ Many of the currently proposed TE strategies are based on the use of hydrogels and porous scaffolds as supports for cell attachment and proliferation. ${ }^{2}$ The use of microparticles in the field of TE has led to several applications such as cell expansion, ${ }^{3}$ release of soluble factors ${ }^{4,5}$ and enhancement of controlled delivery systems properties. ${ }^{6-8}$ Most recently, microparticles have been proposed for cell induced aggregation as injectable systems, ${ }^{9-26}$ organ printing $^{27-29}$ and mesoscale self-assembly, ${ }^{30-32}$ which arose as alternatives to traditional three-dimensional porous scaffolds and hydrogels.

Cell induced aggregation of microparticles is an interesting TE approach since it combines solid structures for cell attachment

${ }^{a} 3$ Bs Research Group-Biomaterials, Biodegradables and Biomimetics, AvePark, Zona Industrial da Gandra, S. Cláudio do Barco, Caldas das Taipas, 4806-909 Guimarães, Portugal.E-mail: jmano@dep.uminho.pt

${ }^{b} I B B$, Institute for Biotechnology and Bioengineering, PT Government Associated Laboratory, Guimarães, Portugal

${ }^{c}$ G. I. R. Bioforge, University of Valladolid, Edificio I+D, Paseo de Belén, 1, 47011 Valladolid, Spain

${ }^{d}$ Networking Research center on Bioengineering, Biomaterials and Nanomedicine (CIBER-BBN), Valladolid, Spain with injectability, allowing for the implantation of cells and biomaterials using minimally invasive procedures. Particles can also be used for cell delivery, in the case of previous in vitro cell seeding, and eventually allow for the incorporation and controlled release of bioactive agents, such as growth factors. Injectable microparticles have already been proposed for the regeneration of cartilage, ${ }^{17,20}$ dermal, ${ }^{15}$ hepatic, ${ }^{18}$ adipose $^{10}$ and bone ${ }^{16,19}$ tissues.

Depending on the processing methods used for the production of the particles, several conditions such as size and its distribution range, shape, density, mechanical properties, porosity, among others can be controlled. The most commonly used processing technique for the production of particles is emulsification, ${ }^{33}$ which allows for the fast obtaining of particles. However, low control of the particles final shape (e.g. due to the application of mechanical forces by stirring), wide size distribution and particle aggregation are usual problems of this technique. This method can also compromise the effective biomolecule encapsulation in the particles due to release of the content in the matrix to the bath where the particles are prepared.

A new processing methodology will be used in this work to process particles based on the use of superhydrophobic (SH) surfaces. These surfaces are characterized by a water contact angle higher than $150^{\circ}$, usually with low hysteresis (lower than $\left.10^{\circ}\right){ }^{34,35}$ They have already been proposed for biomedical 
applications such as selective cell adhesion control, ${ }^{36}$ open microfluidic devices ${ }^{37}$ or substrates for high-throughput analysis. $^{38}$ In this work, polystyrene (PS) surfaces ${ }^{37}$ are proposed as part of an innovative method based on the deposition of liquid precursors as spherical droplets in SH surfaces to prepare hydrogel polymeric particles, inspired by water rolling on the lotus leaf, involving basically liquid-air interfaces, as proposed by Song et al. ${ }^{39}$

Several materials, ranging from natural (e.g. gelatin, ${ }^{24}$ chito$\operatorname{san}^{21}$ and collagen ${ }^{22}$ ) to synthetic origin (e.g. PLGA $\left.{ }^{20}\right)$, as well as hybrids ${ }^{25}$ and composites, ${ }^{16}$ have been used for the production of microparticles to be used as injectable systems. Elastin-like recombinamers (ELRs) are genetically engineered polymers ${ }^{40}$ firstly designed and analyzed by Urry. ${ }^{41-43}$ They contain natural elastin aminoacidic domains and are well known for their responsive behavior to several stimuli, namely temperature, in aqueous solution. This temperature-responsive nature has been used in the methodologies employed for the bioproduction and purification of these materials using cycles of dissolution and precipitation by changing the temperature. ${ }^{44}$ The possibility of tailoring their sequence and incorporating bioactive domains has been of major interest. ${ }^{45-47}$ The recombinant nature of such polymers enables the introduction of peptide sequences through genetic engineering to extend their properties, such as RGD (Arg-Gly-Asp) to improve cell adhesion behavior. ${ }^{48}$ These materials have also shown remarkable biocompatibility and mechanical properties similar to natural elastin. ${ }^{49}$ Three-dimensional porous matrices of REVD-containing polymers have been developed for general TE applications, ${ }^{50}$ as well as hydrogels for the encapsulation of chondrocytes ${ }^{51}$ and adipose-derived stem cells. ${ }^{52}$ The crosslinking of ELR matrices has been achieved by $\gamma$ irradiation, ${ }^{53}$ enzymatic crosslinking ${ }^{51}$ and chemical crosslinking with, e.g. hexamethylene diisocyanate (HDI) ${ }^{50}$ For bone TE strategies, Barbosa et al. ${ }^{54}$ have proposed the use of an osteoconductive ELR combined with a chitosan-based injectable formulation. To our knowledge, ELR microparticles combined with cells were never proposed as injectable systems for TE. Cell behavior has proven to be dependent on characteristics of the substrate. For example, pre-commitment for differentiation of stem cells to specific lineages is dependent on the matrix elasticity. ${ }^{55}$ More specifically, Chatterjee et al. ${ }^{56}$ proved that the production of mineralized extracellular matrix (ECM) of an preosteoblast cell line is dependent on the substrate stiffness using a poly(ethylene glycol) (PEG) hydrogel with an array of mechanical properties. In this work, RGD-containing ELR injectable microparticles with distinct stiffness were prepared by varying the crosslinking extent. The aggregation capability and the biological performance of such particles were tested using an osteoblast-like cell line.

\section{Results and discussion}

The ELR used herein, H-RGD6, was designed in order to obtain enhanced cell adhesion by the incorporation of the widely used RGD bioactive domain in its structure (Fig. 1). In two-dimensional conditions, H-RGD6 promotes higher SaOs-2 adhesion and proliferative behavior compared to an analogous ELR without the RGD domain. ${ }^{48}$ Moreover, this polymer has 24 lysines in its structure which allow for crosslinking through the

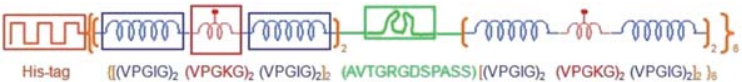

Fig. 1 Schematic representation of an H-RGD6 chain, highlighting the aminoacidic primary structure.

amine groups. The polymer used herein has been previously characterized by sodium dodecyl sulfate polyacrylamide gel electrophoresis (SDS-PAGE), matrix-assisted laser desorption/ ionization-time of flight mass spectroscopy (MALDI-TOF) and peptide sequencing tests. ${ }^{48} \mathrm{H}$-RGD6 particles were obtained by an innovative method based on the SH properties of modified polystyrene (PS) by dropping polymeric solution onto these surfaces (see Experimental section). PS was cut from commercial plastic Petri dishes, which increased the affordability and easiness of the method. The modified PS surfaces showed a water contact angle of $153.2 \pm 4.1^{\circ}$, against the $83.6 \pm 3.2^{\circ}$ of the unmodified PS.

In order to obtain different crosslinking conditions, microparticles were crosslinked with the homobifunctional crosslinker hexamethylene diisocyanate (HDI), which forms covalent links with $\varepsilon$-amines of the polymer lysines. ${ }^{50} \mathrm{HDI}$ is of particular interest for this application since it avoids undesirable specific reactions with possible reactive amino acids such as arginine (R) or aspartic acid (D) involved in cell-adhesion. ${ }^{57}$ Distinct particles were prepared by different times of exposure to the crosslinker. Free amines quantification using trypan blue's ability to bind to free amines was performed in order to assess the number of amines covalently linked to HDI during each crosslinking time. The absorbance of dissolved (non-crosslinked) known amounts of polymer was used to build a calibration curve in order to iterate the number of free $\varepsilon$-amine groups corresponding to the measured absorbance of samples using crosslinked polymer. Particles of the condition R1 showed a crosslinking degree of approximately $22 \%$ which is, as expected, lower than the R2 condition particles, with a crosslinking extent of $60 \%$, as observed in Table 1.

Spherical particles obtained with a controlled volume of $2 \mu \mathrm{L}$, showed a diameter of $1.3 \pm 0.1 \mathrm{~mm}$ and $1.1 \pm 0.1 \mathrm{~mm}$ for $\mathrm{R} 1$ and $\mathrm{R} 2$ crosslinking conditions, respectively. This method for the preparation of the particles allowed to obtain a controlled size distribution of the particles and avoided the exposure of the particles to stirring forces during processing, which usually happens in emulsion and gelation techniques. ${ }^{33}$ The production of smaller particles was achieved by repeated contact of a pipette tip with the SH surface, while the polymer was manually extruded. This envisaged the formation of smaller particles, which resulted, as expected, in a wider size distribution, compared to the controlled volume particles. R1 particles

Table 1 Crosslinking degree of the polymer for each crosslinking condition

\begin{tabular}{llll}
\hline Crosslinking condition & $\begin{array}{l}\text { R0 } \\
\text { (soluble polymer) }\end{array}$ & R1 & R2 \\
\hline $\begin{array}{l}\text { Free lysine amines/H-RGD6 chain } \\
\text { Crosslinking degree (\%) }\end{array}$ & 24 & $\sim 19$ & $\sim 10$ \\
\hline
\end{tabular}


showed an average diameter of $904 \pm 140 \mu \mathrm{m}$, while R2 condition showed an average diameter of $810 \pm 123 \mu \mathrm{m}$. The distribution of sizes of $\mathrm{R} 1$ particles was wider comparing to $\mathrm{R} 2$, which values were concentrated in a $500 \mu \mathrm{m}$ to $900 \mu \mathrm{m}$ range. Smaller particles could be produced by dispensing smaller liquid droplets onto the SH substrate using, for example, a jet sprayer. Electrospraying and electrojetting would particularly be interesting techniques to apply for the production of particles using SH surfaces, since the correct optimization of parameters of these techniques allows for narrow size distributions and for the scaleup of the production of particles. ${ }^{58}$

The variation in time of the swelling of the particles obtained with the two crosslinking conditions was evaluated. Due to the longer crosslinking time, which represents a higher number of covalently bonded amine groups and a decrease in chain length between crosslinking points, $\mathrm{R} 2$ particles were expected to have a lower swelling rate than R1 particles. In Fig. 2 it can be seen that R1 shows an equilibrium swelling of approximately $2000 \%$, and R2 particles of approximately $400 \%$. Besides the swelling rate difference, the time required for the obtaining of equilibrium values for R 1 conditions - about 90 minutes - is lower than the almost 180 minutes necessary for R2 condition.

Dynamic mechanical analysis (DMA) is an adequate tool to characterize the mechanical/viscoelastic properties of polymeric materials. It has been reported that polymeric materials present different behaviors depending on the kind of environment where they are tested. ${ }^{59-61}$ DMA experiments were performed in a hydrated environment and at $37^{\circ} \mathrm{C}$ in order to assess how samples behave in conditions closer to physiological environment. Fig. 3 presents the viscoelastic behavior of ELR cylinders with different crosslinking degrees. The storage modulus $\left(E^{\prime}\right)$ of all samples tends to increase with increasing frequency: for R $1 E^{\prime}$ increases from 75 to $215 \mathrm{kPa}$ and for $\mathrm{R} 2 E^{\prime}$ increases from 215 to $650 \mathrm{kPa}$. The increase of the modulus with frequency has been previously observed in hydrogels ${ }^{62,63}$ and reflects the more difficult reaction of the conformational mobility of the chains for shorter variations of the periodical load. Two possible explanations were considered for this fact: the first one is related to the incompressibility of water. At low frequencies, the water probably has the time to be expelled from the porous polymeric structure. However, at higher frequencies, the water keeps entrapped in the pores, and the modulus increases due to the

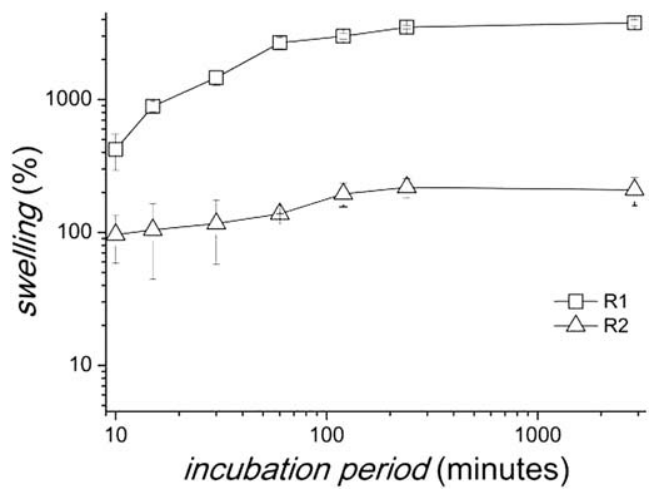

Fig. 2 Swelling values of the particles as a function of immersion time in PBS at $37^{\circ} \mathrm{C}$.

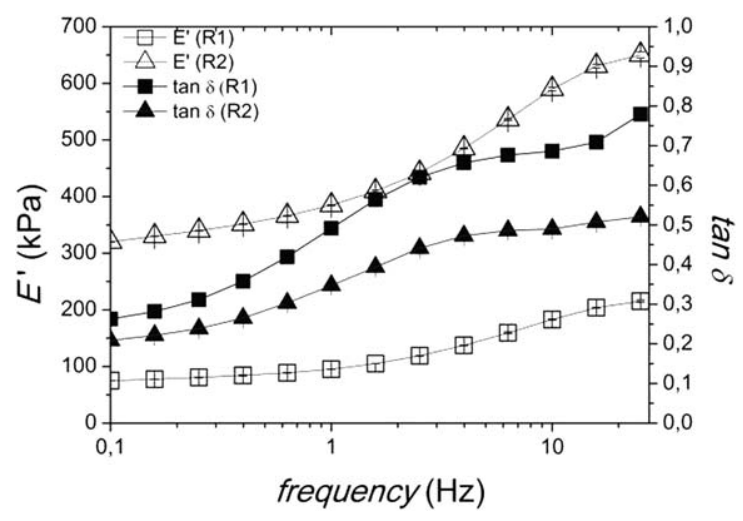

Fig. 3 The storage modulus $\left(E^{\prime}\right)$ and loss factor $(\tan \delta)$ of ELR cylinders crosslinked with two different extents (R1 and R2), according to the applied frequency, measured at $37^{\circ} \mathrm{C}$, immersed in PBS.

higher incompressibility of the construct in such conditions. Fig. 3 shows that in all the frequency range, the storage modulus is higher for the more crosslinked hydrogel, which corresponds to the typical stiffness effect found in more crosslinked systems. ${ }^{64,65}$

The influence of the crosslinking degree on the loss factor (tan $\delta$ ) is also presented in Fig. 3. The loss factor is the ratio of the amount of energy dissipated by viscous mechanisms relative to energy stored in the elastic component providing information about the damping properties of the material. For all formulations, $\tan \delta$ increases with the increase of frequency. The values of $\tan \delta$ reveal a clear viscoelastic behavior of the hydrogels. The higher values of $\tan \delta$ for R 1 may be explained by the higher dragging effect of water present in the structure of the more hydrated hydrogel. ${ }^{66,67}$ Similarly to the obtained results, an increase in the values of the loss factor $(\tan \delta)$ with frequency was reported in rheological measurements performed on a pentapeptide hydrogel-20 Mrad crosslinked (GVGVP) 260 - by Urry et al. ${ }^{68}$ In the applied range of frequencies $(1 \mathrm{~Hz}-25 \mathrm{~Hz})$, the authors observed an exponential increase of the values of this parameter for temperatures higher than the transition temperature of the polymer. In addition, simultaneous increase of the elastic modulus and loss factor with the increase of frequency has been observed in biological samples such as liver and uterus tissue. ${ }^{69,70}$

The different crosslinking extent of the particles was expected to affect cell response. Cell culture was performed using SaOs-2, an osteoblast-like cell line widely used for bone TE preliminary studies. Static conditions were used during cell culture, although the particles were re-suspended in the first hour after seeding every 15 minutes to guarantee that the cells could reach all the particles in the tube and enhance a uniform cell attachment.

Substrate mechanical properties have been proved to influence cell behavior by mechanisms of mechanotransduction which may affect cells focal adhesion strength and morphology. ${ }^{55,71}$ Surfaces with lower stiffness and capability of adsorbing proteins from culture medium are generally believed to be less supportive for cell attachment and proliferation. ${ }^{56}$ Particles swelling influences the surface tension. It is widely accepted that polymer surfaces with an intermediate surface energy can better support cell attachment and proliferation than those with higher or lower 
surface energies, since low protein binding will occur on more hydrophilic surfaces while more hydrophobic surfaces will induce adsorption of non-adhesive proteins and denaturing of adhesive proteins. In addition, it should be noted that different cell types might respond to a substrate differently. ${ }^{72}$

The influence of the two different crosslinking degrees of the particles was tested in the adhesion, viability, proliferation and alkaline phosphatase (ALP) expression of SaOs-2. In order to mimic closer physiological-like conditions, proliferation studies were performed in complete medium, i.e. in the presence of serum proteins. In this case, the possibility of implanting the particles directly in the defect was considered, excluding the pre-seeding of cells, such as primary or stem cells. This would ideally require the optimization of the in vitro cell culture conditions in order to obtain the most efficient cell adhesion. Cell response was tested for 3, 7 and 14 days of cell culture.

DNA quantification gives a measure of the amount of DNA in the samples, which directly correlates to the cell number. A significant increase in proliferation in $\mathrm{R} 2$ condition was observed from day 3 to day 7 . From day 7 to day 14 a stabilization of proliferation could be seen in both conditions (Fig. 4). This could be explained by the confluence of the cells on the microparticles surface after 7 days of cell culture - see SEM images in Fig. 5A and B. The micrographs in Fig. 5 illustrate the morphology and distribution of the cells cultured in the two materials for different time points. In both conditions, after 7 days of cell culture, cells showed spread morphology and fully occupied the surface of the particles. MTS test (cell viability test) showed a significant increase of cell viability from day 3 to day 7, which means that residues of crosslinker were not present in the cell medium impairing cell viability. After 14 days of cell culture both conditions R1 and R2 presented the cells grouped in clusters and layers, respectively, with a rounder shape compared to the morphology in day 7. These cell clusters in some cases detached from the particles, which could be both seen by SEM and confocal microscopy (data not shown). Due to the fast cell proliferation observed at day 7 and to the lack of space for further proliferation, cells were forced to grow in layer-like structures, preventing the access of cells to oxygen and medium

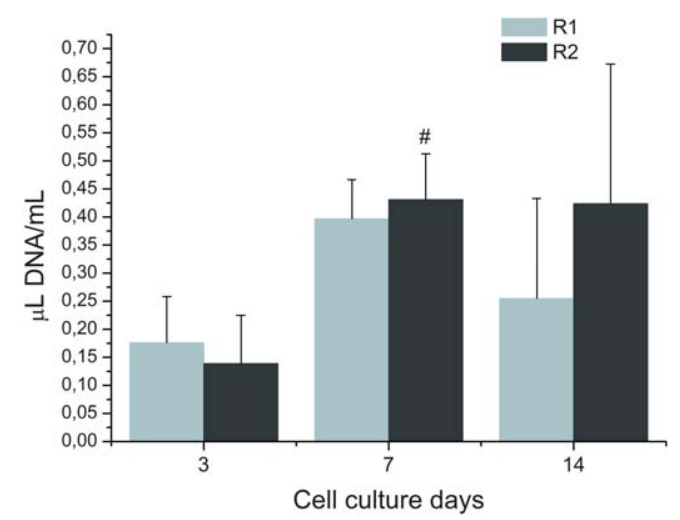

Fig. 4 DNA concentration per $\mathrm{mL}$ of cell lysate after different cell culture time points. Differences were considered statistically significant for $p<0.05$. The nomenclature \# is applied when the value correspondent to a condition in a time point is significantly different from the value of the same condition in the previous time point.
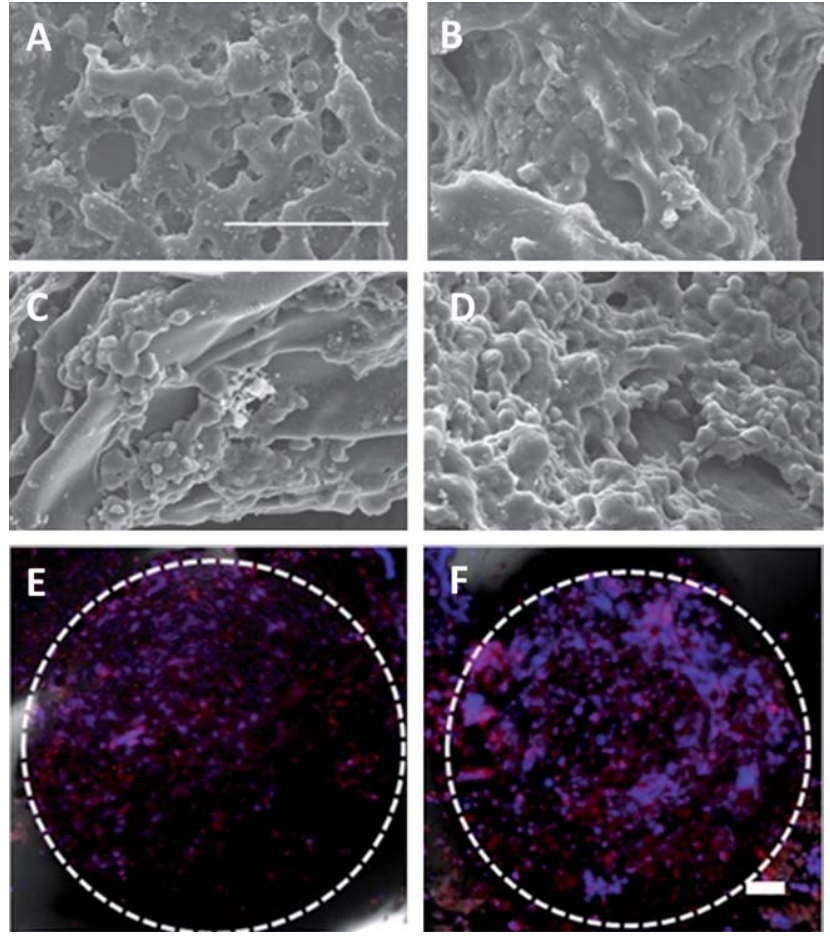

Fig. 5 (A) and (B) Images obtained by SEM of the surface of the R1 and $\mathrm{R} 2$ particles, respectively, after 7 days of culture with $\mathrm{SaOs}-2$ cells. (C) and (D) Images obtained by SEM of the surface of the R1 and R2 particles, respectively, after 14 days of culture with SaOs-2 cells. (E) and (F) correspond to confocal microscope images of entire particles after 14 cell culture days of R1 and R2 conditions, respectively. (A) Scale bar is valid for all SEM images. (F) scale bar is valid for (E). All scale bars correspond to $100 \mu \mathrm{m}$.

nutrients. However, after the detachment of these cell agglomerates, it is expected that the surface would be refilled with cells with spread morphology. Although the particles did not show any weight loss in phosphate buffer saline (PBS) up to 14 days, an analysis of the polymeric sequence in Expasy PeptideCutter Software (Swiss Institute of Bioinformatics) allowed for the search of the enzymes that could cut the sequence, leading to enzymatic degradation in vivo. Thrombin, an enzyme present in the blood plasma cuts the sequence in the RGD domain. Since the polymer has a molecular weight around $60 \mathrm{kDa}$, fragments of an average molecular weight of $10 \mathrm{kDa}$ are expected to be formed in in vivo conditions after the cleavage of the chain by this enzyme, since each polymeric chain has 6 RGD domains. These peptidic fragments $(<30 \mathrm{kDa})$ would probably be excreted by urine. Moreover, enzymes such as neutrophil elastases (which cleave peptide sequences in Valine-Xaa and Alanine-Xaa sites, present in this polymer) would probably also cleave the polymer during the immune recognition of the biomaterial after implantation.

Confocal laser scanning microscopy was performed in order to assess cell distribution in the surface of the particles. After 14 days of cell culture, condition R2 showed a uniform cell distribution on the surface of the particles (Fig. 5F), while in condition R1 some parts of the particle had lower cell density (Fig. 5E). Moreover, in condition R2 the presence of cells around the 
particles, linking several particles could be observed, while in R1 condition this could not be seen.

The osteogenic expression of SaOs-2 for the two crosslinking conditions was evaluated quantifying ALP production, which is an earlier marker of osteogenic behavior. SaOs-2 are characterized by the expression of high levels of ALP, dependent on the cell density. ${ }^{73}$ Both conditions showed an increase in production of ALP until day 7, but in the case of R1, the production of the enzyme decreased significantly, while in R2 the value stabilized, comparing to day 7 . The decrease in $\mathrm{R} 1$ condition may be a consequence of loss of cell viability due to the referred lack of space for proliferation, leading cells to a rounder morphology that may impair the production of the enzyme. Another possibility corresponds to the typical cyclic behavior of ALP in osteogenic cells, in which the drop of ALP concentration corresponds to the synthesis of pre-mineralization osteogenic markers. ${ }^{74}$ ALP values were more elevated in condition R2, which might be explained by the substrate properties of these particles (Fig. 6): bone-related cells would prefer less hydrated and stiffer substrates.

To prove that an in situ scaffold could be formed by agglomeration of the particles by cells, environmental SEM (ESEM) was used to observe the structure after 7 and 14 days of cell culture in hydrated conditions, guaranteeing that the particles would not shrink in the dehydration process (mandatory in conventional SEM analysis) and that the cell bonds between the particles would not be damaged.

After 7 days, using the $\mathrm{R} 2$ condition, it was possible to detect cells that link particles together (see Fig. 7A and B). Such "cellular crosslinkings" led to three-dimensional structures of agglomerated particles possessing mechanical integrity. The confocal image in Fig. 7C shows that the connection between the particles is maintained after 14 days of culture. The micrograph in Fig. 7D shows a representative image of agglomerated particles by cell bonds and extracellular matrix.

In conclusion, two types of RGD-containing ELR particles could be prepared by the variation of the crosslinking extent,

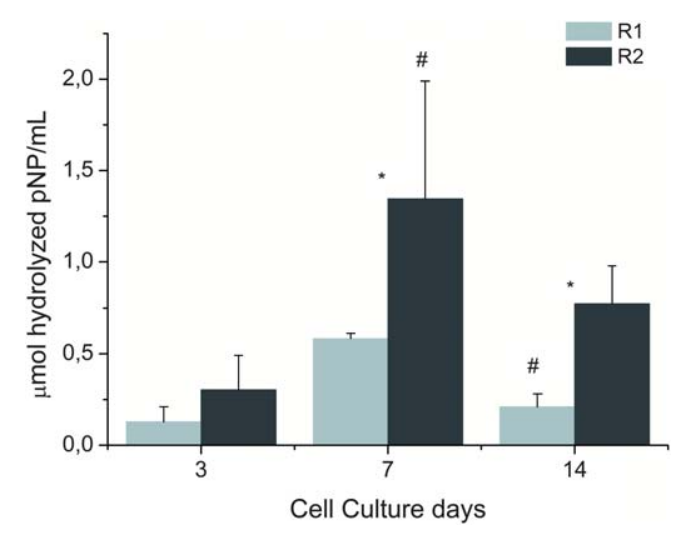

Fig. 6 ALP concentration per $\mathrm{mL}$ of cell lysate after different cell culture time points. Differences were considered statistically significant for $p<$ 0.05 . The nomenclature * is applied when both crosslinking conditions (R1 and R2) have significantly different values in the same time point. The nomenclature \# is applied when the value correspondent to a condition in a time point is significantly different from the value of the same condition in the previous time point.
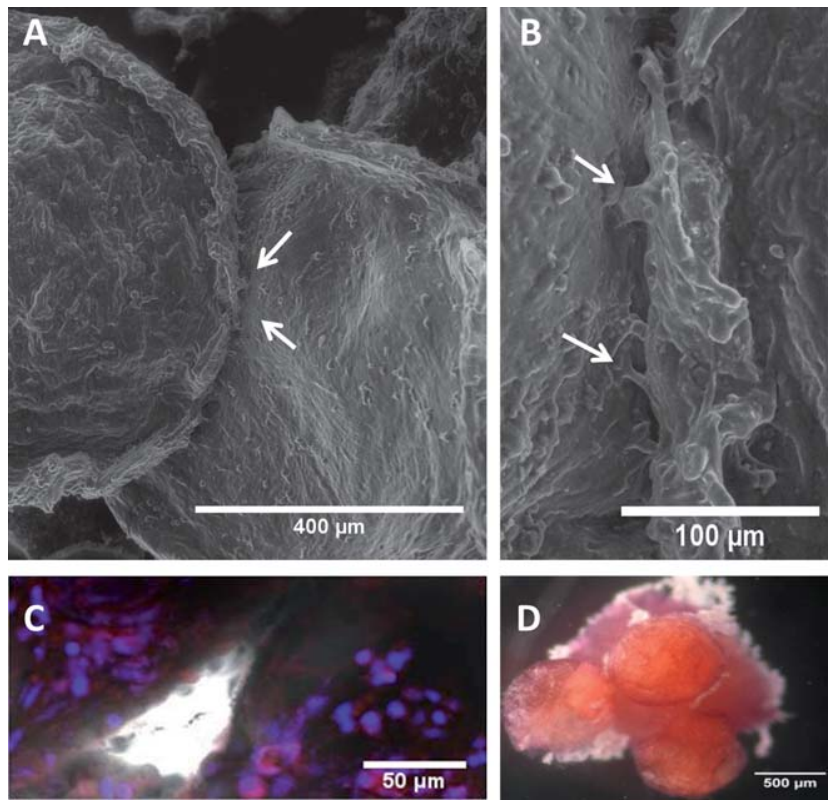

Fig. 7 (A) Image obtained by ESEM of two particles (R2 condition) agglomerated by SaOs-2 cells after 7 days of cell culture. The arrows highlight some regions where cells are connecting two particles. (B) Amplification of (A) in the particles interface. (C) Confocal microscopy image of 3 particles interface after 14 days of cell culture. (D) Photograph of particles agglomerated by cells after 14 days of cell culture.

which affected the particles' swelling, viscoelastic behavior and surface chemistry properties. The response of an osteoblast-like cell line was improved in the more crosslinked particles (condition R2), and structures composed by cell-aggregated particles were observed in this condition after 7 days of cell culture.

\section{Experimental}

\section{Synthesis of the elastin-like recombinamer (H-RGD6)}

The expressed and purified polymer-H-RGD6 - contained 6 monomers of RGD and a histidine tag (His-tag). With a theoretical molecular weight of $60661 \mathrm{Da}$, this polymer contains the following charged groups: 6 aspartic acids (D), 24 lysines (K) and 7 histidines $(\mathrm{H})$. The structure of the polymer is represented in Fig. 1.

\section{Expression, production and purification of H-RGD6}

The expression, production and purification conditions of $\mathrm{H}$ RGD6 were adapted from McPherson et al. ${ }^{44}$ and Girotti et al. ${ }^{75}$ An E. coli strain-BLR(DE3), from Novagen-genetically modified for the expression of H-RGD6 was expanded in modified terrific broth (TB) medium (from Pronadisa) with $0.8 \%$ $(\mathrm{v} / \mathrm{v})$ of glucose and $0.05 \%(\mathrm{v} / \mathrm{v})$ of ampicillin, in $500 \mathrm{~mL}$ Erlenmeyers, at $37^{\circ} \mathrm{C}, \mathrm{pH} 7$.

The optical density of the culture was measured at $600 \mathrm{~nm}$ (OD600) until the value was constant for, at least, three measurements. Afterwards, the culture was concentrated by centrifugation and lysed by ultrasonic disruption. Cycles of cold/ warm $\left(4^{\circ} \mathrm{C} / 40{ }^{\circ} \mathrm{C}\right)$ centrifugations were performed for polymer 
purification. The polymer was then frozen at $-20{ }^{\circ} \mathrm{C}$ and freezedried.

\section{Production of H-RGD6 microparticles}

Production and characterization of polystyrene superhydrophobic surfaces. Superhydrophobic surfaces were prepared by a phase inversion method, ${ }^{36}$ as described elsewhere ${ }^{37}$ Briefly, a $70 \mathrm{mg} \mathrm{mL}^{-1}$ PS in tetrahydrofuran (THF) (from Riedel-deHaën) solution was prepared and then mixed with ethanol (from Panreac) in a $2: 1.3$ proportion. Some drops of the final solution were dropped in PS surfaces and after 10 seconds the surface was immersed in ethanol for one minute. The final surface was dried with a soft nitrogen flow. The surface water contact angle was measured by the sessile drop method using $6 \mu \mathrm{L}$ of ultrapure water, in an OCA 15+ goniometer (DataPhysics) at room temperature.

Preparation of the H-RGD6 particles. A solution of $10 \%(\mathrm{w} / \mathrm{w})$ of H-RGD6 in ultrapure water was prepared. Two different procedures for the production of particles were adopted, either for the preparation of: (i) controlled size particles, by the deposition of $2 \mu \mathrm{L}$ of the polymer in the $\mathrm{SH}$ surface, using a digital micropipette; (ii) lower sized particles, by the repeated contact between the surface and the pipette tip until the total extruding of the $5 \mu \mathrm{L}$ of the polymeric solution per surface. In both cases, the particles on the surfaces were frozen at $-80{ }^{\circ} \mathrm{C}$ and freeze-dried. The content of particles corresponding to $10 \mu \mathrm{L}$ of solution was placed in $1.5 \mathrm{~mL}$ tubes.

A volume of $1 \mathrm{~mL}$ of $10 \%(\mathrm{v} / \mathrm{v})$ of HDI (Sigma) in 2-propanol (Panreac) solution was poured in each tube containing the particles for different periods of time, in order to obtain two different crosslinking conditions: R1 (30 minutes of crosslinking) and R2 (2 hours of crosslinking). In order to avoid interparticle crosslinking, during crosslinking reaction particles were shaken every 15 minutes and the position of the tube was kept horizontal so agglomeration of particles in the bottom of the tube was avoided, and particles had less contact points between each other. The crosslinking reaction was stopped with excess of 2propanol, removing the HDI/2-propanol solution and washing with $1 \mathrm{~mL}$ of 2-propanol three times.

Distilled water was added to 2-propanol in increasing ratios $(30 \%, 50 \%, 70 \%, 90 \%(\mathrm{v} / \mathrm{v})$ of water) for 15 minutes each, maintaining the mixtures at $4{ }^{\circ} \mathrm{C}$. Afterwards, the particles remained in distilled water overnight at $4{ }^{\circ} \mathrm{C}$.

Sterilization was performed in 70\% ethanol (v/v) for at least 12 hours, followed by washing in PBS (Sigma) at $4{ }^{\circ} \mathrm{C}$ overnight. The complete particle production process is represented in Fig. 8.

\section{Physico-chemical characterization of microparticles}

Swelling tests. The samples were weighed in freeze-dried state ( $1 \mathrm{mg}$ per sample) and after several time points of incubation in PBS at $37^{\circ} \mathrm{C}$. The excess of water was removed using a filter paper. The swelling was determined using the following equation after 10 minutes, 15 minutes, 30 minutes, 1 hour, 2 hours and 48 hours of immersion in PBS solution.

$$
S(\%)=\frac{\text { hydrated weight }- \text { dry weight }}{\text { dry weight }} \times 100
$$

Diameter measurement. The microparticles were incubated at $37^{\circ} \mathrm{C}$ in PBS. After several time points, the wet microparticles were isolated and observed in a Stereo Microscope Stemi 1000 PG-Hitec Zeiss. Diameters were measured using ImageJ

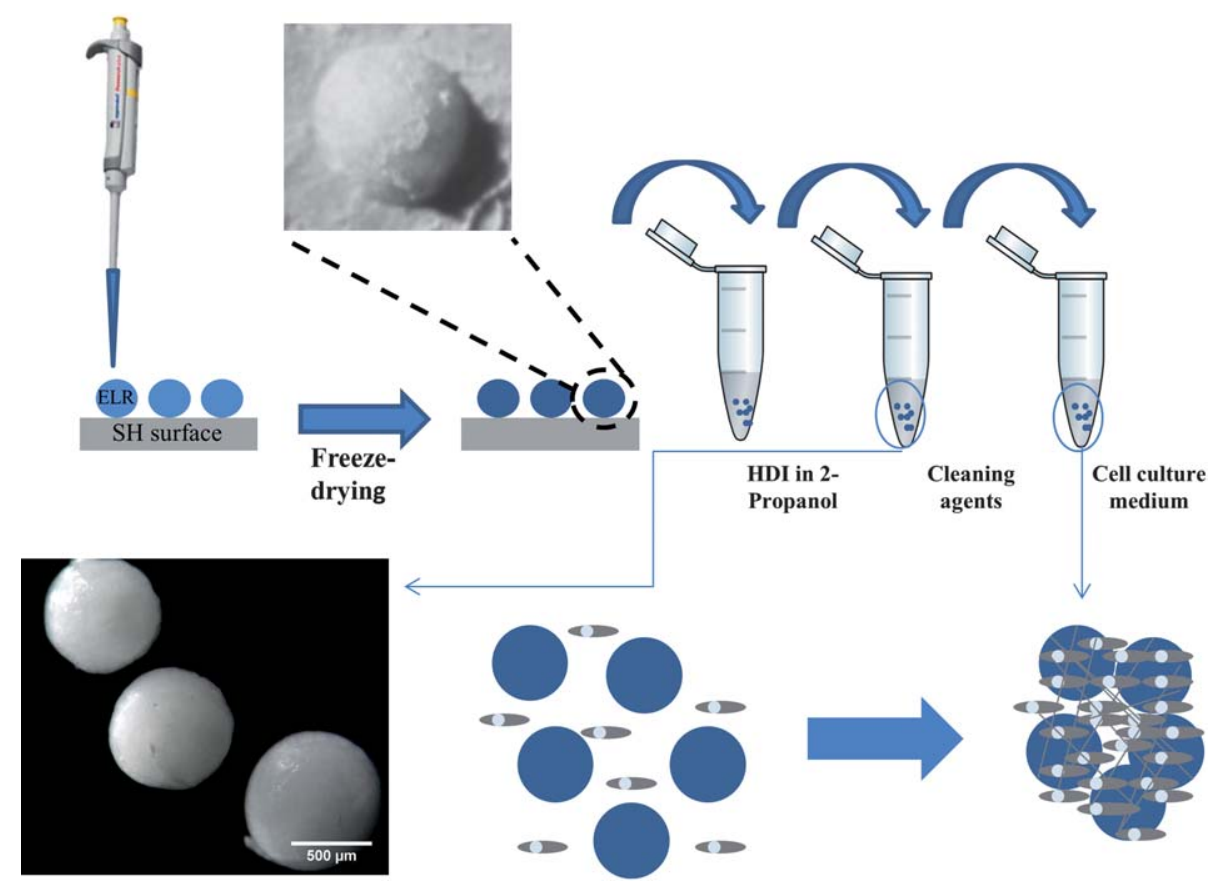

Fig. 8 Schematic representation of the several steps performed to obtain ELR microparticles and cell seeding. A representative photograph of particles ( 2 condition) produced by this method is also shown. 
software. All samples had at least 15 particles and measurements were performed in triplicate $(n \geq 45)$.

Mechanical properties. The viscoelastic measurements were performed using a TRITEC8000B DMA from Triton Technology (UK), equipped with the compressive mode. The measurements were carried out at $37^{\circ} \mathrm{C}$. For the preparation of geometrically well-defined samples, the ELR solution was pipetted into polyvinyl chloride tubes and all the samples were processed with the same protocol as the particles. Cylinders were cut in cylindrical shapes with about $3.5 \mathrm{~mm}$ diameter and $3 \mathrm{~mm}$ thickness (measured accurately for each sample). ELR cylinders were always analyzed immersed in a liquid bath placed in a Teflon ${ }^{\circledR}$ reservoir. ELR cylinders were first immersed in a PBS solution at $37{ }^{\circ} \mathrm{C}$. The geometry of the samples was then measured and the samples were clamped in the DMA apparatus and immersed in the PBS solution. After equilibration at $37^{\circ} \mathrm{C}$, the DMA spectra were obtained during a frequency scan between 0.1 and $30 \mathrm{~Hz}$. The experiments were performed under constant strain amplitude $(50 \mu \mathrm{m})$. A small preload was applied to each sample to ensure that the entire scaffold surface was in contact with the compression plates before testing and the distance between plates was equal for all scaffolds being tested. Three samples were used for each condition.

Crosslinking degree analysis. The lysine quantification in the samples was carried out by the trypan blue precipitate method. ${ }^{76}$ This reagent has affinity to free amines, present in the lysines of soluble polymer. The test was performed immersing the crosslinked samples (correspondent to $0.2 \mathrm{mg}$ of polymer prepared from a $10 \%(\mathrm{w} / \mathrm{w})$ solution), as well as soluble polymer in trypan blue $0.4 \%$ (Invitrogen) diluted $50 \times$ in distilled water overnight at $37{ }^{\circ} \mathrm{C}$. The supernatant absorbance was measured at $580 \mathrm{~nm}$ in a microplate reader (Synergy HT, Izasa). A standard curve was prepared with different quantities of soluble polymer in $1 \mathrm{mg}$ $\mathrm{mL}^{-1}$ solution in Milli-Q water, and the number of amines in 0.2 $\mathrm{mg}$ of crosslinked polymer was compared to the number of amines in $200 \mu \mathrm{L}$ of non-crosslinked polymer $\left(1 \mathrm{mg} \mathrm{mL}^{-1}\right.$, which corresponds to the same amount of polymer). The crosslinking degree was calculated by:

$\mathrm{CL}(\%)=$

$\underline{\left(\mathrm{NH}_{3}^{+} \text {noncrosslinked solution }\right)-\left(\mathrm{NH}_{3}^{+} \text {crosslinked solution }\right)}$ $\mathrm{NH}_{3}^{+}$noncrosslinked solution

$\times 100$

\section{Biological performance of the developed particles}

Cell culture and seeding. The human osteosarcoma osteoblastlike cell line SaOs-2 (supplied by European Collection of Cell Cultures, UK) was used. The cells were expanded in $75 \mathrm{~cm}^{2}$ cell culture T-flasks in Dulbecco's Modified Eagle's Medium (DMEM, Sigma, USA) with phenol red supplemented with $10 \%$ of heat-inactivated fetal bovine serum (FBS, Biochrom AG).

The microparticles were preincubated in sterile PBS overnight at room temperature in $1.5 \mathrm{~mL}$ tubes. A cell suspension of SaOs- $2\left(3 \times 10^{5}\right.$ cells per $\left.\mathrm{mL}\right)$ was prepared by trypsinization $(0.25 \%$ trypsin in EDTA solution, Sigma). The cells were concentrated by centrifugation and resuspended in culture medium. After the removal of the PBS from the tubes, $1 \mathrm{~mL}$ of the cell suspension was added to each tube. In the first hour of incubation, the microparticles were resuspended in the medium every 15 minutes to enhance the cell attachment uniformity in the particles. The open tubes - to which the cap was previously cut in sterile conditions - were placed inside $3 \mathrm{~mL}$ tubes, whose cap was left half-open for gas exchange in the incubator. The system was kept on a $\mathrm{CO}_{2}$ incubator (at $37{ }^{\circ} \mathrm{C}, 5 \% \mathrm{CO}_{2}$ ) for the time period previously established: 3,7 or 14 days. The culture medium was changed every 2 days.

Cell viability assessment-(3-(4,5-dimethylthiazol-2-yl)-5-(3carboxymethoxyphenyl)-2-(4-sulfophenyl)-2H-tetrazolium) (MTS) viability test. Cell viability for each culturing time was determined using the CellTiter 96 AQueous One Solution Cell Proliferation Assay (Promega, USA). This assay is based on the bioreduction of a tetrazolium compound, MTS, into a watersoluble brown formazan product.

After cell seeding and washing with PBS, samples were incubated in a MTS/phenol red-free DMEM solution for 3 hours. The absorbance was read at $490 \mathrm{~nm}$ in a microplate reader (Synergy HT, Izasa).

Cell proliferation assessment-DNA quantification. Quant$\mathrm{iT}^{\mathrm{TM}}$ Picogreen ${ }^{\circledR}$ (from Invitrogen) reagent is an ultrasensitive fluorescent nucleic acid stain for the quantification of dsDNA (double strand DNA). The excitation wavelength is $480 \mathrm{~nm}$ and the emission is $545 \mathrm{~nm}$.

The cells in the microparticles were lysed by freeze-thawing cycles in distilled water. The DNA content of the cell lysates was quantified using a DNA quantification kit-Quant-iT ${ }^{\mathrm{TM}}$ Picogreen ${ }^{\circledR}$. The frozen particles were sonicated for 15 minutes and vortexed to allow cellular DNA into the solution. The fluorescence measurements were carried out using Quant-iT ${ }^{\mathrm{TM}}$ Picogreen ${ }^{\circledR}$ established protocol in a microplate reader (Synergy HT, Izasa).

Cell morphology - scanning electron microscopy (SEM). For SEM analysis, samples were fixed in $2.5 \%$ of glutaraldehyde for 30 minutes at $4{ }^{\circ} \mathrm{C}$ and further dehydrated using gradients of ethanol $(50 \%, 70 \%, 90 \%$ and $100 \%), 15$ minutes each, and let dry overnight. The samples were coated with a thin film of gold and further analyzed using SEM equipment (Fei Nova 200).

Cell distribution on the particles-confocal laser scanning microscopy. The samples were fixed in $2.5 \%$ of glutaraldehyde for 30 minutes at $4{ }^{\circ} \mathrm{C}$ and then stained with rhodamine B (Sigma) for intracellular actin staining for 30 minutes and, after washing with PBS, with 4',6-diamidino-2-phenylindole (DAPI) (Invitrogen) for cell nucleus staining for 1 minute.

The samples were washed and kept in PBS until confocal laser scanning microscopy analysis

Assessment of the formation of cell induced aggregates - environmental scanning electron microscopy (ESEM). 3, 7 and 14 days after cell seeding the samples were fixated in $2.5 \%$ glutaraldehyde 
in PBS for 30 minutes. The samples were kept in PBS at $37^{\circ} \mathrm{C}$ until the ESEM analysis (Philips-FEI/Quanta 400).

Alkaline-phosphatase quantification. Alkaline phosphatase (ALP) is the most frequently used biochemical marker of osteoblastic bone formation. The activity of this marker is evaluated using $p$-nitrophenol assay. $p$-Nitrophenylphosphate, which is colourless, is hydrolysed by ALP at $\mathrm{pH} 10.5$ at $37^{\circ} \mathrm{C}$ to form free $p$-nitrophenol, which is yellow in color. This reaction is stopped using sodium hydroxide $(\mathrm{NaOH})$.

ALP activity assays were performed on cell lysates. All reagents were purchased from Sigma. All samples were prepared in triplicate and compared against $p$-nitrophenol standards. The absorbance was read at $405 \mathrm{~nm}$ on a plate reader (Synergy HT, Izasa) to determine the enzyme concentration per $\mathrm{mL}$ of cell lysate.

Statistical analysis. All data are presented as mean \pm standard deviation (s.d.) for $n=3$. Assessment of normality distribution of the population was performed by Shapiro-Wilk test. Comparison of conditions R1 and R2 was performed by non-parametric test Mann-Whitney (comparison of two unpaired samples). To compare the different time points of the same condition nonparametric Kruskal-Wallis test was performed (comparison of three or more unpaired samples).

\section{Conclusions}

Microparticles of a RGD-containing ELR (H-RGD6) were prepared depositing polymeric solution on superhydrophobic PS surfaces.

Two different microparticle crosslinking extents $-22 \%$ and $60 \%$-were achieved controlling the time of exposure of the $\mathrm{H}$ RGD6 to the hexamethylene diisocyanate, which influenced the average diameter, swelling behavior and the mechanical properties of the microparticles. With higher crosslinking extents, lower diameters and swelling rate were obtained, in contrast with the elastic modulus $\left(E^{\prime}\right)$, which was higher than the one obtained in $20 \%$ crosslinking extent condition.

The response of a human osteosarcoma cell line with osteogenic properties was tested for particles in both crosslinking conditions, assessing cell proliferation and ALP expression in distinct time points. The cell viability and osteogenic expression were significantly higher in the particles with a higher crosslinking extent. Furthermore, the morphology and the spatial distribution of the cells after 14 days of culture in the particles with a higher crosslinking showed that this condition was clearly favorable for SaOs-2 growth. The main goal of this work was to prove the cell induced aggregation of the microparticles in order to assess the possible formation of an in situ scaffold after implantation in a defect. The formation of cell induced aggregation of microparticles was successfully achieved in the R2 condition.

In conclusion, osteoblast-like cell lines show enhanced osteogenic expression and spatial distribution in the presence of stiffer ELR substrates, allowing the formation of microparticle aggregates by cell "crosslinking", which might represent an interesting solution for bone TE strategy.

\section{Acknowledgements}

We acknowledge financial support through the European regional development fund (ERDF) from EU, the MICINN (projects MAT 2007-66275-C02-01, MAT 2007-61604, MAT 2009-14195-C03-03 and PSE-300100-2006-1), the JCyL (projects VA034A09 and VA030A08), the CIBER-BBN (project CB06-010003), the JCyL and the Instituto de Salud Carlos III under the "Network Center of Regenerative Medicine and Cellular Therapy of Castilla and León". The financial support from Fundação para a Ciência e Tecnologia (Portugal), through projects PTDC/FIS/68517/2006 and PTDC/QUI/68804/2006, is also acknowledged.

\section{References}

1 R. Langer and J. P. Vacanti, Science, 1993, 260, 920-926.

2 Tissue Engineering, ed. C. van Blitterswijk, Elsevier, London, 1st edn, 2008.

3 A. van Wezel, Nature, 1967, 216, 64-65.

4 V. E. Santo, A. M. Frias, M. Carida, R. Cancedda, M. E. Gomes, J. F. Mano and R. L. Reis, Biomacromolecules, 2009, 10, 1392-1401.

5 T. P. Richardson, M. C. Peters, A. B. Ennett and D. J. Mooney, Nat. Biotechnol., 2001, 19, 1029-1034.

6 B. Soontornworajit, J. Zhou and Y. Wang, Soft Matter, 2010, 6, 4255-4261.

7 J. Liu, D. Meisner, E. Kwong, X. Y. Wu and M. R. Johnston, Biomaterials, 2007, 28, 3236-3244.

8 G. S. Fullana, H. Ternet, M. Freche, J. L. Lacut and F. Rodriguez, Acta Biomater., 2010, 6, 2294-2300.

9 D. M. G. Cruz, J. L. E. Ivirico, M. M. Gomes, J. L. G. Ribelles, M. S. Sánchez, R. L. Reis and J. F. Mano, J. Tissue Eng. Regener. Med., 2008, 2, 378-380.

10 H. J. Chung and T. G. Park, Tissue Eng., Part A, 2009, 15, 1391-1400.

11 K. W. Chun, H. S. Yoo, J. J. Yoon and T. G. Park, Biotechnol. Prog., 2004, 20, 1797-1801.

12 T. Gan, Y. Guan and Y. Zhang, J. Mater. Chem., 2010, 20, 59375944.

13 G. A. Howard, R. T. Turner, J. E. Puzas, F. Nicholas and D. J. Baylink, J. Am. Med. Assoc., 1983, 249, 258-259.

14 S. Huang and F. Xiaobing, J. Alloys Compd., 2010, 493, 246-251.

15 F. R. M. Huss, E. Nyman, J. S. C. Bolin and G. Kratz, J. Plast. Reconstr. Aesthetic. Surg., 2010, 63, 848-857.

16 S. W. Kang, H. S. Yang, S. W. Seo, D. K. Han and B. S. Kim, J. Biomed. Mater. Res., 2008, 85, 747-756.

17 S. W. Kang, J. R. Yoon, J. S. Lee, H. J. Kim, H. W. Lim, H. C. Lim, J. H. Park and B. S. Kim, J. Biomater. Sci., Polym. Ed., 2006, 17, 925939.

18 M. Kawase, N. Michibayashi, Y. Nakashima, N. Kurikawa, K. Yagi and T. Mizoguchi, Biol. Pharm. Bull., 1997, 20, 708-710.

19 M. Kucharska, K. Walenko, B. Butruk, T. Byrnk, M. Heliak and T. Ciach, Mater. Lett., 2010, 64, 1059-1062.

20 R. M. Mercier, H. R. Constantino, M. A. Tracy and L. J. Bonassar, Biomaterials, 2005, 26, 1945-1952.

21 F. L. Mi, Y. C. Tan, H. F. Liang and H. W. Sung, Biomaterials, 2002, 23, 181-191.

22 M. Overstreet, A. Sohrabi, A. Polotsky, D. S. Hungerford and C. G. Frondoza, In Vitro Cell. Dev. Biol.: Anim., 2003, 39, 228-234.

23 S. K. Sahoo, A. K. Panda and V. Labhasetwar, Biomacromolecules, 2005, 6, 1132-1139.

24 P. Sommar, S. Pettersson, C. Ness, H. Johnson, G. Kratz and J. P. E. Junker, J. Plast. Reconstr. Aesthetic. Surg., 2010, 63, 10361046.

25 H. Tan, J. Wu, D. Huang and C. Gao, Macromol. Biosci., 2010, 10, $156-163$.

26 X. H. Zhu, C. H. Wang and Y. W. Tong, J. Biomed. Mater. Res., 2006, 82, 7-16.

27 J. W. Nichol and A. Khademhosseini, Soft Matter, 2009, 5, $1312-$ 1319. 
28 S. J. Moon, S. K. Hasan, Y. S. Song, F. Xu, H. O. Keles, F. Manzur, S. Mikkilineni, J. W. Hong, J. Nagatomi, E. Haeggstrom, A. Khademhosseini and U. Demirci, Tissue Eng., Part C, 2009, 15, 1-9.

29 V. Mironov, R. P. Visconti, V. Kasyanov, G. Forgacs, C. J. Drake and R. R. Markwals, Biomaterials, 2009, 30, 2164-2174.

30 A. P. Rago, D. M. Dean and J. R. Morgan, Biotechnol. Bioeng., 2009, 102, 1231-1241.

31 N. C. Rivron, J. Rouwkema, R. Truckenmüller, M. Karperien, J. D. Boer and C. A. van Blitterswijk, Biomaterials, 2009, 30, 4851-4858.

32 A. Khademhosseini and J. G. Fernandez, Adv. Mater., 2010, 22, 2538-2541.

33 D. Y. S. Chau, K. Agashi and M. Shakesheff, Mater. Sci. Technol., 2008, 24, 1031-1044.

34 C. Dorrer and J. Rühe, Soft Matter, 2008, 5, 61-61.

35 P. Roach, N. J. Shirtcliffe and M. I. Newton, Soft Matter, 2008, 4, 224-240.

36 W. Song, D. D. Veiga, C. A. Custódio and J. F. Mano, Adv. Mater., 2009, 21, 1830-1834.

37 N. Oliveira, A. I. Neto, W. Song and J. F. Mano, Appl. Phys. Express, $2010,3,085205$.

38 A. I. Neto, W. Song and J. F. Mano, Soft Matter, 2011, DOI: 10.1039/ C1SM05169E.

39 W. Song, A. C. Lima and J. F. Mano, Soft Matter, 2010, 6, 58685871.

40 C. A. Custódio, C. M. Alves, R. L. Reis and J. F. Mano, J. Tissue Eng. Regener. Med., 2010, 4, 316-323.

41 D. W. Urry, J. Phys. Chem. B, 1997, 101, 11007-11028.

42 D. W. Urry and T. M. Parker, J. Muscle Res. Cell Motil., 2002, 23, $543-559$.

43 J. C. Rodríguez-Cabello, J. Reguera, M. Alonso, T. M. Parker, D. T. McPherson and D. W. Urry, Chem. Phys. Lett., 2004, 388, 127-131.

44 D. T. McPherson, C. Morrow, D. S. Minehan, J. G. Wu, E. Hunter and D. W. Urry, Biotechnol. Prog., 1992, 8, 347-352.

45 F. Arias, V. Reboto, S. Martín, I. López and J. Rodríguez-Cabello, Biotechnol. Lett., 2006, 28, 687-695.

46 J. C. Rodríguez-Cabello, J. Reguera, A. Girotti, M. Alonso and A. M. Testera, Prog. Polym. Sci., 2005, 30, 1119-1145.

47 A. Girotti, J. Reguera, J. Rodríguez-Cabello, F. Arias, M. Alonso and A. Testera, J. Mater. Sci.: Mater. Med., 2004, 15, 479-484.

48 R. R. Costa, C. A. Custódio, A. M. Testera, F. J. Arias, J. C. Rodríguez-Cabello, N. M. Alves and J. F. Mano, Adv. Funct. Mater., 2009, 19, 3210-3218.

$49 \mathrm{~K}$. Trabbic-Carlson, L. A. Setton and A. Chilkoti, Biomacromolecules, 2003, 4, 572-580.

50 L. Martín, M. Alonso, A. Girotti, F. J. Arias and J. C. RodríguezCabello, Biomacromolecules, 2009, 10, 3015-3022.

51 M. K. McHale, L. A. Setton and A. Chilkoti, Tissue Eng., 2005, 11, 1768-1779.

52 H. Betre, S. R. Ong, F. Guilak, A. Chilkoti, B. Fermor and L. A. Setton, Biomaterials, 2006, 27, 91-99.
53 J. Lee, C. W. Macosko and D. W. Urry, Macromolecules, 2001, 34, $4114-4123$.

54 J. S. Barbosa, A. Ribeiro, A. M. Testera, M. Alonso, F. J. Arias, J. C. Rodríguez-Cabello and J. F. Mano, Adv. Eng. Mater., 2010, 12, B37-B44.

55 A. J. Engler, S. Sen, H. L. Sweeney and D. E. Discher, Cell, 2006, 126, $677-689$.

56 K. Chatterjee, S. Lin-Gibson, W. E. Wallace, S. H. Parekh, Y. J. Lee, M. T. Cicerone, M. F. Young and C. G. Simon, Jr, Biomaterials, 2010, 31, 5051-5062.

57 P. J. Nowatzki and D. A. Tirrell, Biomaterials, 2004, 25, 1261-1267.

58 N. Arya, S. Chakraborty, N. Dube and D. S. Katti, J. Mater. Chem., 2009, 88, 17-31.

59 J. F. Mano, N. M. Neves and R. L. Reis, in Biodegradable Systems in Tissue Engineering and Regenerative Medicine, ed. R. L. Reis and J. S. Román, CRC Press, 2005.

60 J. F. Mano, R. L. Reis and A. M. Cunha, in Polymer Based Systems on Tissue Engineering, Replacement and Regeneration, ed. R. L. Reis and D. Cohn, Kluwer Academic Publishers, Netherlands, 2002, vol. 86, pp. 139-164.

61 J. F. Mano, Macromol. Biosci., 2008, 8, 67-76.

62 H. Sa-Lima, S. G. Caridade, J. F. Mano and R. L. Reis, Soft Matter, 2010, 6, 5184-5195.

63 J. V. Cauich-Rodriguez, S. Deb and R. Smith, Biomaterials, 1996, 17, $2259-2264$

64 R. M. Silva, G. A. Silva, O. P. Coutinho, J. F. Mano and R. L. Reis, J. Mater. Sci.: Mater. Med., 2004, 15, 1105-1112.

65 S. G. Caridade, R. M. P. da Silva, R. L. Reis and J. F. Mono, Carbohydr. Polym., 2009, 75, 651-659.

66 N. M. Alves, J. L. G. Ribelles, J. A. G. Tejedor and J. F. Mano, Macromolecules, 2004, 37, 3735-3744.

67 S. Ghosh, V. Gutierrez, C. Fernandez, M. A. Rodriguez-Perez, J. C. Viana, R. L. Reis and J. F. Mano, Acta Biomater., 2008, 4, 950-959.

68 D. W. Urry, T. Hugel, M. Seitz, H. E. Gaub, L. Sheiba, J. Dea, J. Xu and T. Parker, Philos. Trans. R. Soc., B, 2002, 357, 169-184.

69 Z. K. Miklos, et al., Phys. Med. Biol., 2006, 51, 3683.

70 Z. K. Miklos, et al., Phys. Med. Biol., 2004, 49, 4207.

71 A. L. Hook, N. H. Voelcker and H. Thissen, Acta Biomater., 2009, 5, 2350-2370.

72 T. Ishizaki, N. Saito and O. Takai, Langmuir, 2010, 26, 8147-8154.

73 S. B. Rodan, Y. Imai, M. A. Thiede, G. Wesolowski, D. Thompson, Z. Bar-Shavit, S. Shull, K. Mann and G. A. Rodan, Cancer Res., 1987, 47, 4961-4966.

74 F. Causa, P. A. Netti, L. Ambrosio, G. Ciapetti, N. Baldini, S. Pagani, D. Martini and A. Giunti, J. Biomed. Mater. Res., Part A, 2006, 76, 151-162.

75 A. Girotti, J. Reguera, F. J. Arias, M. Alonso, A. M. Testera and J. C. Rodriguez-Cabello, Macromolecules, 2004, 37, 3396-3400.

76 W.-C. Shen, D. Yang and H. J. P. Ryser, Anal. Biochem., 1984, 142, 521-524. 